\title{
A model to promote activity competence in elders.
}

Ruth E. Levine

Thomas Jefferson University

Laura N. Gitlin

Thomas Jefferson University

Follow this and additional works at: https://jdc.jefferson.edu/otfp

Part of the Occupational Therapy Commons

Let us know how access to this document benefits you

\section{Recommended Citation}

Levine, Ruth E. and Gitlin, Laura N., "A model to promote activity competence in elders." (1993).

Department of Occupational Therapy Faculty Papers. Paper 47.

https://jdc.jefferson.edu/otfp/47

This Article is brought to you for free and open access by the Jefferson Digital Commons. The Jefferson Digital Commons is a service of Thomas Jefferson University's Center for Teaching and Learning (CTL). The Commons is a showcase for Jefferson books and journals, peer-reviewed scholarly publications, unique historical collections from the University archives, and teaching tools. The Jefferson Digital Commons allows researchers and interested readers anywhere in the world to learn about and keep up to date with Jefferson scholarship. This article has been accepted for inclusion in Department of Occupational Therapy Faculty Papers by an authorized administrator of the Jefferson Digital Commons. For more information, please contact: JeffersonDigitalCommons@jefferson.edu. 


\section{A Model to Promote Activity Competence in Elders}

\author{
Ruth E. Levine, Laura N. Gitlin
}

Key Words: chronic disease $\bullet$ home care services

This paper describes an occupational therapy bomebased intervention in which purposeful activities were used to promote adaptation and competence in older adults with chronic disabilities. Seven bome care therapists visited 17 randomly selected, communityliving elders who were chronically disabled and who volunteered to participate in the program. The number of visits ranged from 3 to 10 and occurred over a 3-month period according to clients' needs and wishes. Therapists enbanced their ability to enter the client's social and cultural system by using participantobservation techniques and collaboratively identified activities. Therapists documented each bome visit with a structured fieldnote form. An analysis of 112 fieldnotes indicated that therapists were able to understand a client's needs; this understanding resulted in small qualitative gains in areas identified as important by the client. Reilly's concept of an activity continuum was a useful framework from which to work with this population. The implications for program development, treatment outcomes, and accountability with this approach promote improved future treatment planning with the elderly with chronic disability.

Ruth E. Levine, EdD, OTRL, FAOTA, is Professor and Chairman, Department of Occupational Therapy, College of Allied Health Sciences, Thomas Jefferson University, Philadelphia, Pennsylvania. (Mailing address: Room 824 Edison, 130 South 9th Street, Philadelphia, Pennsylvania 19107)

Laura N. Gitlin, PhD, is Associate Professor, Department of Occupational Therapy, Research Coordinator, College of Allied Health Sciences, Thomas Jefferson University, Philadelphia, Pennsylvania.

Tbis aricle was accepted for publication July 27, 1992.
Today, 1 in every 10 Americans is chronically disabled, and this number is expected to rise dramatically by the 21 st century as the population ages Estimates from national health surveys indicate that close to $13 \%$ of community-living elders aged 65 years or older report difficulty with walking or with at least one self-care task, whereas $17.5 \%$ report difficulty with at least one instrumental daily life activity, such as meal preparation, housekeeping, or shopping. Although most elders function independently, the proportion of those who do so diminishes with age. The percentage of those unable to function without some type of assistance rises dramatically to $34.5 \%$ for those aged 85 years and older (Leon \& Lair, 1990). As advances in technology prolong life, it is anticipated that the number of elderly persons with chronic illness and disability will steadily increase. Chronic illness presents unique social, psychological, and physical issues that are distinct from those presented in acute illness (Corbin \& Strauss, 1988). It necessitates long-term care over time where prognosis is often uncertain, function and dysfunction are episodic, progressive deterioration in physical well-being occurs, and quality of life is "intrusively" affected for both caregivers and chronically ill persons (Strauss, 1975, p. 35). Professionals who assist persons in accommodating and adapting to their disabilities will be important participants in the effort to provide quality care and contain rising health care costs.

This paper describes an occupational therapy homebased intervention in which purposeful activities were used to promote adaptation and competence in older adults with chronic disabilities. The intervention is based on an application of Reilly's (1974) concept of an activity continuum in which the specific concerns and issues identified by older adults as affecting the quality of their daily lives form the basis of therapeutic actions. The intervention was developed and evaluated as part of a research project that examined home-based strategies for older home-bound elders. Seven home care occupational therapists visited 17 community-living elders who were chronically disabled. The subjects were randomly selected and volunteered to participate in the program.

\section{Background and Significance of Approach}

Current service provision and treatment approaches to chronic illness continue to be based on an acute care, medical model focus. This focus emphasizes therapistdriven intervention strategies to promote independence in functional abilities and a symptom-based and timelimited approach to treatment. However, an emerging body of literature has identified unique conditions confronted by older adults with multiple chronic illnesses that challenge the acute care model. Research studies varying widely in methodological approaches have identified the need for health professionals to develop a care perspective that extends beyond current temporal 
boundaries of service, one that incorporates the specific goals and issues of persons and their caregivers in the management of daily activities and complex life changes presented by chronicity and aging (Becker \& Kaufman, 1988; Chiou \& Burnett, 1985; Hasselkus, 1988; Kaufman, 1983; Ory \& Williams, 1989). Ory and Williams (1989) suggested that, although the goals of older adults often seem qualitative to a therapist, basing treatment on small goals may encourage and maintain interest in the older patient who is working through the disability recovery process. By focusing on small goals that are important to the person, a therapist provides a series of successful experiences that are immediately relevant to the person's life. The identification and incorporation of patient and caregiver goals in the treatment process challenges therapists to assume a collaboration-based approach in the development of intervention strategies.

The concept of collaboration has emerged in the health care literature as a pivotal factor in treatment effectiveness (Gitlin \& Corcoran, 1991; Peloquin, 1990; Shelton, Jeppson, \& Johnson, 1989). Identification of patient goals in occupational therapy is important to assure a successful therapeutic process. Therapists often use therapeutic activities to motivate a person through the occupational therapy process (Barris, 1982; Barris et al., 1985; Dunning, 1972; Meyer, 1922). Activities or goaldirected occupations are the interface between the person and his or her environment. Activity participation offers feedback and behavioral evidence of the person's effect on the environment (Barris, 1982, 1986; Kielhofner \& Burke, 1980). Barris (1986) described occupational therapy as a "created environment" (p. 48) where the therapist offers options for the person to engage in activities. Feelings of mastery and satisfaction, which are derived from participation, then become a positive influence on future behavior. Persons become motivated and gain a positive sense of self when an activity matches their own goals for recovery and their interests and needs. In this approach, the choice of activity and its fit with the person's sense of self are critical to successful treatment. A series of studies by Nelson and colleagues showed that episodic involvement in an exercise activity was enhanced when a meaning was attached to that activity (Nelson, 1988; Nelson \& Peterson, 1989). In these studies, meaning seemed to stimulate further investment, selffulfillment and pleasure, and, hence, positive treatment outcomes. The literature on activity and aging provides further evidence that older adults participate more readily in activities that are important to them and that provide or reinforce a sense of identity and self (Barris, 1986; Heppe \& Ray, 1986).

The development of a meaningful activity for patient participation is the most complex aspect of therapeutic intervention. This therapeutic process can be seen as a hierarchy of occupational performance (Christiansen \& Baum, 1991; Levine \& Brayley, 1991; Llorens, 1986) in which occupation refers to engagement in activities (Nelson, 1988). The most basic component of the hierarchy is the introduction of an activity or specific action or pursuit designed to capture the client's interest quickly. The next layer of the hierarchy is the performance of a series of interrelated activities or tasks that have a common purpose and are mutually understood and recognized by persons (Levine \& Brayley, 1991). Barris et al. (1985) maintained that persons participate in these actions "to satisfy either external societal requirements or internal motives to explore and be competent" ( $p$. 49). The highest level of the occupational performance hierarchy contains activities that contribute to or reflect the doer's participation in a role. Such activities fulfill role or social expectations or requirements and are personally satisfying (Levine \& Brayley, 1991, p. 621).

When developing activities, tasks, and roles for a client, the therapist must consider the influence of the environment or the "composite of all external forces and influences affecting the competence and maintenance of an individual" (Hopkins \& Smith, 1983, p. 920). White (1959, 1964, 1971) defined competence as efficacy in meeting environmental demands. To enhance competence, occupational therapists adjust the level of press of the environment during an activity by using carefully selected activity choices, adapting the materials or process, grading the activity upward or downward, designing parallel choices, using repetition, and assisting the patient with verbal and nonverbal cues. Murray developed the concept of press, which refers to the demands or forces in the environment that activate the physical, interpersonal, or social needs of a person and thus affect behavior in that environment (Murray, Barrett, \& Hamburger, 1938). Competence develops as the person explores, manipulates, and learns to adjust behaviors to meet external demands (Christiansen, 1991).

\section{Description of Intervention Program}

As part of a study to evaluate home-based occupational therapy strategies, seven therapists from across the Unites States volunteered to participate as home visitors to elderly persons with chronic disabilities living in their communities. Therapists participated in a 5-day training program, sponsored by the funding source, in which they were oriented to the conceptual basis of the intervention. Through lecture, group discussion, and case presentations, therapists were instructed in the collaboratively driven, activity-based approach of the intervention. Therapists were instructed not to treat the person, but to listen and build a trusting relationship from which to identify the daily problems for which clients expressed interest in receiving assistance. Participatory observation techniques were introduced to the therapists to enhance their ability to enter the client's social and cultural system (Gitlin \& Corcoran, 1991; Levine \& Gitlin, 1990; Spradley, 
1979). Therapists were also taught to use assessment instruments that included closed-ended and open-ended questions to establish a collaborative relationship and gain insight into the client's interests and needs

\section{Description of Clients}

After training, therapists returned to their respective work place and contacted a supervisor or director of a home care agency, public or subsidized housing, or retirement or rehabilitation center to request a pool of clients who might benefit from a home-based activity program. Clients had to be 65 years of age or older with a chronic illness that had been medically stable for one year. Each therapist randomly selected up to 10 clients from this pool. Therapists then randomly selected up to 5 clients to participate in the intervention. Seventeen clients agreed to be visited and evaluated for their living situation, social network and time use, and their ability to perform self-care and instrumental activities of daily living. Fifty-nine percent were women and $41 \%$ were men. Seventy-seven percent lived alone: $59 \%$ were widowed, $12 \%$ divorced, and $6 \%$ never married. The remaining $23 \%$ were married and lived with their spouses. Eighty-eight percent of the clients were white, $6 \%$ were black and $6 \%$ represented a wide range of ethnic backgrounds. More than half (59\%) of the clients lived in either an apartment building or an apartment in a house, whereas $24 \%$ lived in housing for the elderly. Although chronically disabled, $53 \%$ classified their health as good to excellent, whereas only $18 \%$ rated their health as poor. Clients reported a wide range of disabilities: $53 \%$ indicated arthritis as a primary, secondary, or tertiary diagnosis, and 18\% indicated polio as a primary diagnosis. Other primary diagnoses included Parkinson disease, diabetes, brain injury, and high blood pressure.

\section{Visit Pattern}

Each occupational therapist visited from one to five clients. Every client received an evaluation and an average of 7 visits, each of which lasted an average of $45 \mathrm{~min}$. The number of visits ranged from 3 to 10 with a mode of 6 . Therapists were not bound by fiscal constraints, made visits on their own time according to the needs and wishes of the client, and determined with the client the appropriate number of visits. The average number of days between visits was 14 , the range was from 5 to 40 days and the mode and median between visits was 7. Except for four clients, all had at least 1 or more visits scheduled with more than 20 days between visits. This scheduling pattern was based on client need and indicates the importance of fexibility in timing service provision to this population. Also, administrative time was not wasted on closing and opening cases even if service was interrupted by several weeks.

\section{Documentation}

Therapists completed a fieldnote form for each visit that documented the following: time, visit number and date, place, adverse conditions, observations of client, observations of environment, activities, personal themes, and preparation for next visit (see Table 1). This documentation served two purposes: it provided a mechanism for therapists to reflect about their own interactions and activity choices, and it assisted the investigators in evaluating the components of the intervention and its outcomes as reported by the therapists.

The investigators reviewed 112 fieldnote forms to identify three aspects of the intervention process: activities that clients engaged in, a description of the activity that was introduced or pursued during each visit, and the outcome of the visit.

\section{Intervention Process}

Four phases of intervention parallel the occupational performance hierarchy (Kielhofner, 1985; Reilly, 1974). Each phase is described here with examples from the therapists' fieldnotes.

Phase 1: Exploration-Activity as a means to learn about the client. During Visits 1-3, exploratory activities were used to evaluate the client, attempt to understand client concerns, and generate interest by the client. Visit I, an evaluation tool that involved both structured and unstructured questions, was used to structure activity. These questions probed the client's daily activities and the meaning of objects and tasks. A functional assessment

\section{Table 1}

Items Included in Therapist Fieldnotes

\begin{tabular}{|c|c|}
\hline Itenss & Description \\
\hline Tince & Time when therapist arrived and left. \\
\hline Visic number & Visits numbered consecurively. \\
\hline Pláce & Place of visit. \\
\hline $\begin{array}{l}\text { Adverse } \\
\text { conclituons }\end{array}$ & $\begin{array}{l}\text { Nocation of environmental forces that may have } \\
\text { impinged on dient's performance. }\end{array}$ \\
\hline $\begin{array}{l}\text { Observations } \\
\text { of client. }\end{array}$ & $\begin{array}{l}\text { Included physical scatus, affece, or mood of care- } \\
\text { giver or family }\end{array}$ \\
\hline $\begin{array}{l}\text { Obsicrvation } \\
\text { of environment }\end{array}$ & $\begin{array}{l}\text { Objects and how they were used, tasks and social } \\
\text { groups client was involved in, and cultural as- } \\
\text { pects of the cnvironment. }\end{array}$ \\
\hline Aclivitics & $\begin{array}{l}\text { Activities used during session, description of any } \\
\text { new activitics client engaged in during therapist's } \\
\text { absence, client's reaction to activities incroduced } \\
\text { during the session, description of therapist's re- } \\
\text { flections on activity choice and use of self. }\end{array}$ \\
\hline Personal themes & $\begin{array}{l}\text { Description of themes, statements, and concerns } \\
\text { that provide insight as to the therapist's under- } \\
\text { standing of the client's self-icientity, values, and } \\
\text { interests. }\end{array}$ \\
\hline $\begin{array}{l}\text { Preiparation for } \\
\text { next visit }\end{array}$ & $\begin{array}{l}\text { Icjeas for next visit and lise of questions therapist } \\
\text { wanted to explore. }\end{array}$ \\
\hline
\end{tabular}


of self-care was obtained using the Functional Independence Measure (FIM), which rates level of independence on a 7-point scale (FIM, 1987). This rating scale was also used to evaluate performance of 15 instrumental activities of daily living.

During Visit 2, therapists raised questions and formulated hypotheses about the client and caregivers. This questioning process indicated that therapists were actively working to understand the client, the environment, and the client's interests. Some examples from therapists' notes are as follows:

She told stories that I had a hard time understanding [in terms of] their relevance to the evaluation questions.

She was more animated in conversation about family members than about herself.

[After he expressed interest in indoor gardening] He is going to be an interesting person to get to know.

During Visit 3, therapists began to test initial hypotheses and to further explore client interests through the introduction of therapist-generated or client-generated activity ideas. Throughout these initial activities, therapists and clients searched for role boundaries. Therapists who joined in the client's activity tended to develop rapport more readily and were able to amend their own activity ideas to assure client success. Examples of activities introduced by therapists included dressing the upper extremity, planning exercise groups, arranging flowers, playing card games, looking through an equipment cata$\log$, gardening indoors, playing an electric organ that the therapist brought, reminiscing, making bread dough, sharing family photographs, and sharing food. Therapists continued to question their understanding of the client, the level of rapport achieved, and how to work more effectively and collaboratively. One therapist wondered, "Why is he discussing [the] Depression era and World War II in all three of my visits?" and later wrote "He is a challenge and I'm not sure I'll be able to do anything." Another indicated, "I am still building rapport with her. I think she is somewhat suspicious yet. Needs to trust me more." "How comfortable will she become with me? I her? She surprises me already with things she discusses with me."

A clear example of rapport building is illustrated by the following therapist's description. The therapist had noted the client's past interest in music during the evaluation interview and encouraged the client to discuss this interest and her previous role as a pianist. In the next visit, the therapist brought her own electronic organ so the client could exercise this old skill. "We experimented with her religious music used for notes and chords. She chose a country music base [sic] chord and beat while I played 'Amazing Grace' to it. We laughed and enjoyed ourselves. Rapport building."

Phase II: Competence-Creating Tasks. By Visit 4, the focus of the interventions tended to be clearer to the therapist and the fieldnotes indicated their growing sense of confidence. As one therapist explained,

The importance of the opportunity to try our activity in the home setting, whether an adaptation or a renewed skill, has been reinforced with each client. Talking about proposed change generally produces a negative response. The key is therapist creating a cognitive bridge between old habits and roles and accommodation to new physical or emotional needs.

Another therapist exclaimed, "I feel I hit this one on the head."

Throughout visits 4 through 6 , the fieldnotes reveal that therapists were able to incorporate the client's culture and environment into treatment. Whereas rapport building and achieving an understanding of the client's goals and values were concerns in visits 1 through 3 , the issue in this phase of the intervention was control. Control can be defined as taking charge and guiding and directing the process and outcome of the intervention. In working with chronically ill clients, it may be advantageous to share control and ultimately relinquish it so that clients become empowered to take more responsibility for the management of their care. In this phase, a shift in control was evident as therapists and clients continued to collaborate. The following passage indicates how one therapist guided the therapeutic process but was flexible enough to share control and foster increased client participation in decision making: "I offered suggestions when needed, but let him have control for organizing, combining, and categorizing his items. . . I would like to be more structured with an activity next time or we'll never get anywhere."

Once trust was established, therapists could focus on adaptations and physical accommodations, at times assuming a more directive role and offering suggestions or displaying samples or pictures to better explain their ideas. One therapist commented, "The surprising thing this time was that she asked me to help her see if she could go up a step or two. This was something I was curious about and prepared to help her with." The client had serious problems and the therapist talked with her about "scooting up and down the stairs." The client thought this would be a good idea.

An evaluation of the fieldnotes revealed that, when therapists were unable to collaborate and relinquish control, therapeutic outcomes did not appear to be as positive and meaningful to the client or to be perceived as effective by the therapist. In 5 of the 17 cases, therapists allowed the clients to direct the activities throughout the intervention. In the other 12 cases, the therapists used the client's activities during the first two visits to gain trust and rapport. These therapists allowed the clients to direct the activities and become participants in choices such as card playing, reorganizing a closet, talking about the client's family, or having coffee and cake and socializing. Therapists introduced their own ideas after they felt that 
they had gained some rapport. At times, therapists expressed feelings of guilt because they were not directing and controlling the provision process. Integrating the client's ideas with the therapist's often seemed to be mutually beneficial. However, it also created anxiety in some therapists because responsibility for decision making was being shared.

Examples of activities that were introduced once rapport and trust had been established included buying incontinence pants, adjusting the volume knob of the television, raising the height of the client's bed, and demonstrating Kegel exercises to improve incontinence. Each of these activities reflected an increased level of comfort and trust that had been gained through the activities pursued by the therapist and client.

Visit 6 was primarily devoted to teaching and reinforcing previously introduced ideas. Activities were used to skillfully link the client's daily tasks and interests. Therapists emphasized feelings of competence to develop activities into habits. The theme that emerged during this visit was the increase in positive results based on the therapist's understanding of the client's preferred way of doing things. One therapist said, "I appear to be a motivator for him to take charge in doing self-care activity." A former gardener with left hemiplegia took the therapist to see his sprouting indoor herb garden, and the client who had not played the organ in years shared her playing with another friend.

Phase III: Achievement-Establishing Roles. The theme that emerged from visits 7 through 10 was "tucking in loose ends." One therapist stated: "I saw myself as agent of change and facilitator for client and family."

In two cases, the clients were eager to receive life review tapes that the therapist used during reminiscence activity. Therapists also reviewed adaptive equipment use and reinforced the link between activity interests and roles. "I wasn't sure how the volunteer suggestions would go so I brought other things also. Glad those worked."

One therapist took a client to the mall and taught her to use the automatic teller machine. For some clients, the role of church attendee, exercise group organizer, organ player, Bible group participant, photographer, and independent dresser were restored. Other clients developed new interests such as making string art and socializing with neighbors.

Phase IV: Final Visit: Saying Good-bye. Therapists reviewed their accomplishments during this visit. Contacts with appropriate referral sources were arranged and some therapists arranged for further, less intense communication. One therapist wrote, "1 think he has been thinking more about things he can't do ... than the things he can." This statement captures the therapist's investment in maximizing the client's competence and suggests that occupational therapy raised new issues that might be addressed later once these ideas were further integrated into the client's life.

\section{Summary of Intervention Outcomes}

An evaluation of the fieldnotes revealed that the clients who participated in the intervention engaged in a range of activities such as making wine, visiting relatives, attending church, making bread, doing craft work, socializing, reading, playing bingo, cleaning, doing arm chair exercise, and reading. The great variety of interests and abilities among the members of this group of chronically impaired persons suggests that a treatment focus on functional status provides a limited framework for occupational therapy.

Therapists reported a variety of positive outcomes that were critical for what Ory and Williams (1989) called "small standards of measurement" (p. 68). Examples of these qualitative gains include a client who agreed to volunteer his time, one who renewed socializing with neighbors, and another who organized and directed an exercise group. One woman resumed church attendance, another agreed to make aprons for the occupational therapy department, one man made a series of tapes about his life for family members, and several used adaptive equipment more skillfully, thus enhancing their self-care performance.

There were 10 areas of concern on which therapists tended to focus:

1. Mobility (e.g., getting to church on Sundays)

2. Activities of daily living (e.g., installing and operating shower hose)

3. Instrumental activities of daily living (e.g., using an automatic teller machine)

4. Equipment selection and purchase (e.g., buying incontinence pants, finding an appropriate magnifier and purchasing it for the client)

5. Updating of previously prescribed adaptive equipment (e.g., placing a basket on the front of a walker)

6. Repair of equipment (e.g., repairing reacher and wheelchair, replacing cushion of wheelchair)

7. Expansion of present participation in activities (e.g., encouraging client to use ceramics class to make Christmas presents for family, introducing windowsill herb garden to gardener, encouraging exerciser to organize a group)

8. Introduction of new activities (e.g., tape recording reminiscence activity for family members, making a string art picture)

9. Upgrading or downgrading of previous interests (e.g., introducing electronic keyboard to someone who played the organ, encouraging a photographer to purchase an automatic $35 \mathrm{~mm}$ camera so he could resume taking pictures)

10. Using activities as the basis for building a new area of competence or achievement (e.g., earning money for sewing aprons previously made as gifts). 


\section{Conclusion}

This paper presents an intervention approach that involves extended contact and involvement with an older client with chronic illness. The purpose of extended contact is to derive an insider's perspective, or what is referred to in anthropology as an emic viewpoint, on the issues and concerns of caring for oneself or a family member with chronic illness. In this intervention approach, treatment strategies evolve from an understanding of the meaning of activities and issues of daily life as identified and defined by the client. The fieldnotes revealed that therapists come to understand a client's needs and concerns differently when treatment is not time bound by present-day service provision and fiscal constraints. A client's feelings and story of how he or she is managing unfold within each therapist visit and through the introduction, presentation, reformulation and upgrading of an activity program over time. The visit patterns that emerged indicate the necessity of obtaining optimal flexibility in reimbursement from fiscal intermediaries for such services to the chronically ill. The intervention strategies may appear to have resulted in small qualitative outcomes or accomplishments. However, understood in the context of what is meaningful to these persons, each adaptation, activity introduction, and equipment choice resulted in advancing a client's personal need or goal for achieving a self-care activity, a socialization experience, or a reintegration of their compromised competencies with their former personal identities. These outcomes are important to the person's quality of life.

This client-driven intervention has three major consequences for therapists and traditional therapeutic practice. The first involves that of trust and control. Development of trust generally took two to three visits. Although therapists continued to build rapport over time, they often belittled or minimized their skills and expressed concern with visits that were totally devoted to client needs. Some therapists expressed a loss of control and said they were not "doing anything." Others were initially nondirective and unsure when to assume control and direct the intervention while still preserving the client's role as an active participant. Obtaining the right balance is perhaps the most difficult aspect of a collaborative approach to treatment. In one case, the therapist was not able to obtain the right balance of control until the final visit. Once a collaborative and focused relationship was achieved, therapists tended to report success.

The second issue concerns the accuracy of therapists' interpretations of client concerns. Therapists often felt equivocal regarding their perceptions and understandings of a client's life-style and personal values. It was evident from the fieldnotes that clients rarely expressed their real concerns in direct ways and these concerns often unfolded over time. For example, one therapist discovered a client's problem of incontinence while they were looking at assistive devices in a catalog. The case illustrated the complex ways in which clients perceive their health problems and share intimate concerns with formal health providers. It is up to a skilled professional to read the many cues in the home environment and in a client's presentation of self to discover the client's story.

The third issue raised by this service approach is the potential for conflict because of differences in the therapist's and client's vision of how to frame a problem. This issue can only be resolved if rapport and trust have been achieved and a collaborative relationship has been developed.

One final consideration is that this approach may expose clients to a range of issues and areas in their life that they may not want to have examined by therapists. For example, one therapist who bought incontinence pants for a client on one visit discovered a new feeling of distance after the next visit when she gently inquired about the success of the adaptation.

In conclusion, the intervention is based on the premise that chronic illness presents a set of complex issues that affect the person's personal identity and sense of self as well as issues of daily functioning and self-care. Strict adherence to medical diagnosis and medical functional independence in activities of daily living ignores the multiple needs and concerns that older clients confront in managing their illness over time. The unique skills of occupational therapists as collaborators and listeners who can incorporate client values and interests in therapy provide a critical approach from which to develop innovative and meaningful interventions that promote quality of life for this growing client population. Evaluation of extensive fieldnotes that documented each step of the intervention process from the therapists' perspectives indicated that clients derived positive benefits. Further systematic research is necessary to test the efficacy of the intervention for chronically disabled, medically stable older adults living in the community.

\section{Acknowledgments}

We thank Laura A. Schluter, otr, Ronald A. Stone, mS, orru, Karen F. Barney, MS, OTRL, Jan Stube, OTR, M. Jean Stolzenberg, OTR, Barbara N. Jackson, MS, OTR/, and Anne Long Morris, MPA, OTR, for their assistance.

A version of this paper was presented at the Pennsylvania Occupational Therapy Association Meeting, October 1991, Pittsburgh, Pennsylvania, and at the 72 nd Annual Conference of the American Occupational Therapy Association, April 1992, Houston, Texas.

The research on which this paper is based was supported in part by funds from the American Occupational Therapy Foundation. The opinions expressed in this paper are those of the authors and do not represent the funding agency.

\section{References}

Barris, R. (1982). Environmental interactions: An extension of the Model of Occupation. American Journal of Occupational Therapy, 36, 637-644. 
Barris, R. (1986). Activity: The interface between person and environment. Physical \& Occupational Therapy in Geriatrics, 5(2), 39-49.

Barris, R., Kielhofner, G., Levine, R. E., Neville, A. M. (1985). Occupation as interaction with the environment. In $G$. Kielhofner (Ed.), A Model of Human Occupation: Theory and application (pp. 42-62). Baltimore: Williams \& Wilkins.

Becker, G., \& Kaufman, S. (1988). Old age rehabilitation and research: A review of the issues. Gerontologist, 28, 459-468.

Chiou, I. L., \& Burnett, C. N. (1985). A survey of stroke patients and their home therapists. Pbysical Tberapy, 65, 901-906.

Christiansen, C. (1991). Occupational therapy: Intervention for life performance. In C. Christiansen \& C. Baum (Eds.) Occupational therapy: Overcoming human performance deficits. Thorofare, NJ: Slack.

Christiansen, C., \& Baum, C. (Eds.), (1991). Occupational therapy: Overcoming buman performance deficits. Thorofare, NJ: Slack

Corbin, J.M., \& Strauss, A. (1988). Unending work and care: Managing chronic illness at bome. San Francisco: JosseyBass

Dunning, H. (1972). Environmental occupational therapy. American Joumal of Occupational Therapy, 26, 292-298.

Functional Independence Measure (1987). Guide for use of the Uniform Data Set for Medical Rebabilitation. Buffalo, NY: Data Management Service of the Uniform Data system for Medical Rehabilitation, Research Foundation, State University of New York.

Gitlin, L., \& Corcoran, M. (1991, September/October) Training occupational therapists in the care of the elderly with dementia and their caregivers: Focus on collaboration. Educational Gerontology, 17(5), 591-605.

Hasselkus, B. (1988). Meaning in family caregiving. Gerontologist, 28, 686-691.

Heppe, G., \& Ray, R. O. (1986). Older adult happiness, the contribution of activity: Breadth of intensity. Occupational and Physical Therapy in Gerontology, 4(4), 31-43.

Hopkins, H. L., \& Smith, H. D. (Eds.), (1983). Willard E Spackman's occupational therapy (6th ed.). Philadelphia: Lippincott.

Kaufman, S. (1983). Cultural components of identity in old age. Ethos, 9, 51-87.

Kielhofner, G. (1985). Occupational function and dysfunction. In G. Kielhofner, A model of Human Occupation: Theory and application (pp. 63-75). Baltimore: Williams \& Wilkins.

Kielhofner, G., \& Burke, J. P. (1980). A Model of Human Occupation, Part 1. Conceptual framework and content. Ameri- can Journal of Occupational Therapy, 34, 572-581.

Leon, J., \& Lair, T. (1990). Functional status of the noninstitutionalized/elderly: Estimates of ADL and IADL difficulties. (DHHS Publication No. PHS 90-3462). National Medical Expenditure Survey Research Findings IV, Agency for Health Care Policy and Research. Rockville, MD: Public Health Service.

Levine, R. E., \& Brayley, C. R. (1991). Occupation as a therapeutic medium. In C. Christiansen \& C. Baum (Eds.), Occupational therapy: Overcoming buman performance deficits (pp. 591-631). Thorofare, NJ: Slack.

Levine, R. E., \& Gitlin, L. N. (1990). Home adaptations for persons with chronic disabilities: An educational model. American Joumal of Occupational Therapy, 44, 923-929.

Llorens, L. (1986). Activity analysis: Agreement among factors in a sensory processing model. American Journal of Occupational Therapy, 40, 103-110.

Meyer, A. (1922). The philosophy of occupational therapy. Archives of Occupational Therapy, 1(1), 1-10.

Murray, H. A., Barrett, W. G., \& Hamburger, E. (1938). Explorations in personality. New York: Oxford University Press.

Nelson, D. L. (1988). Occupation: Form and performance. American Journal of Occupational Therapy, 42, 633-641.

Nelson, D. L., \& Peterson, C. Q. (1989). Enhancing therapeutic exercise through purposeful activity: A theoretical analysis. Topics in Geriatric Rebabilitation, 4(4), 12-22.

Ory, M., \& Williams, T. F. (1989, May). Rehabilitation: Small goals, sustained interventions. Annals of the American Academy of Political and Social Science, 60-71.

Peloquin, S. M. (1990). The patient-therapist relationship in occupational therapy: Understanding visions and images. American Joumal of Occupational Therapy, 44, 13-21.

Reilly, M. (1974). An explanation of play. In M. Reilly (Ed.), Play as exploratory learning (pp. 117-149). Beverly Hills: Sage.

Shelton, T., Jeppson, E., \& Johnson, B. (1989). Facilitation of parents/professional collaboration at all levels of health care. In B. E. Hanft (Ed.), Family centered care (pp. 63-66). Rockville, MD: American Occupational Therapy Association.

Spradley, J. P. (1979). The ethnograpbic interview. Fort Worth, TX: Holt, Rinehart \& Winston.

Strauss, A. L. (1975). Chronic illness and the quality of life. St. Louis: Mosby.

White, R.W. (1959). Motivation reconsidered: The concept of competence. Psychological Review, 66, 297-333.

White, R. W. (1964). Sense of interpersonal competence. In R. White (Ed.), The study of lives. New York: Atherton Press.

White, R. W. (1971). The urge toward competence. American Joumal of Occupational Therapy, 25, 271-274. 